\title{
Editorial
}

\section{Prescripción enfermera en el ámbito gerontológico}

Muchas han sido las líneas escritas en los últimos meses sobre la prescripción enfermera en nuestro país. Sonoros los postulados a favor de políticos y organizaciones. Numerosos los asentimientos y reconocimientos "de justicia" de profesionales de diferentes disciplinas en el ámbito de las ciencias de la salud, y muchos y poderosos, a la vista de los resultados, los empecinamientos de algunos herederos del feudalismo sanitario y su presión política y mediática, que han conseguido vencer el primer intento de normalizar y normatizar una situación avalada y afianzada en otros sistemas sanitarios modernos, con notables mejoras en la calidad asistencial.

Países como el Reino Unido, Estados Unidos, Australia, Canadá, Nueva Zelanda, Sudáfrica, Suecia, Dinamarca, Noruega o Irlanda han implantado y consolidado desde hace años la prescripción farmacológica enfermera protocolizada, y su eficacia ha propiciado la aprobación de pacientes, gestores y todos y cada uno de los sectores profesionales sanitarios.

La recién aprobada Ley del Medicamento ha impedido que el blindaje legal de ese ejercicio de prescripción por parte de la enfermera de productos sanitarios y algunos medicamentos, en las condiciones que se debieran establecer, deba esperar, pero mientras sucede... ¿sin interrumpir su práctica?

La prescripción enfermera en el ámbito del cuidado de los más mayores de nuestra sociedad, especialmente en el marco domiciliario y sociosanitario, es una práctica habitual, consolidada y no sometida a reproche desde hace años, pero que entendemos precisaría, para mayor seguridad jurídica, del reconocimiento legal que ahora se nos niega. Una alegalidad consentida durante años ha dado paso a una ilegalidad manifiesta en multitud de situaciones de cada día.

Millares de enfermeros de centros sociosanitarios y de la comunidad vienen seleccionando y aplicando con criterio científico materiales (productos sanitarios) y, a tenor del catálogo vigente, medicamentos en áreas tradicionales de cuidados como la de alimentación y nutrición (oral y enteral), sondajes, ostomías, cuidados orales, movilización, elección de superficies especiales para el manejo de la presión, cuidados de úlceras por presión y otras heridas crónicas y un amplio servicio de - llamemos_ "primeros auxilios" (oxigenoterapia, antieméticos, antisépticos, antitérmicos, etc.) u opciones bajo el generoso y teóricamente responsable espectro de "si se precisa"

Esta situación de manifiesta autonomía en el rol enfermero, cada vez más afianzado y menos discutido, no sin resistencias, ha nacido - quiero pensar- del respeto que conquista una formación (farmacológica incluida) de altura que le permite asumir competencias que le son propias, y no por dejación de otros, ante situaciones "poco gloriosas".

La legalización de la prescripción enfermera de los numerosos productos sanitarios y algunos medicamentos utilizables en este marco de atención facilitará la optimización de los recursos, reconocerá y reforzará el juicio enfermero y estimulará un uso todavía ascendente en el ámbito gerontológico, de práctica clínica basada en los dinámicos dictados de la ciencia, mejorando la calidad de la atención dispensada; además, que nadie tema: no mermará el crédito y respeto de otros, tradicionales y hasta la fecha todavía únicos, prescriptores en este país.

El amparo legal de una práctica cotidiana sigue pendiente de rúbrica.

J. Javier Soldevilla Agreda Director de Gerokomos 